\title{
Jogos digitais na escola: a utilização como objetos de aprendizagem no ensino da matemática
}

\author{
Kátia Cilene da Silva ${ }^{1}$, Mylani Nathalini Dantas $\operatorname{Costa}^{1}$ \\ ${ }^{1}$ CCEN- Universidade Federal Rural do Semi-Árido (UFERSA) \\ Caixa Postal 1039 - 59.631-970 - Mossoró - RN - Brazil \\ katiacs@ufersa.edu.br, mylani_net@hotmail.com
}

\begin{abstract}
The present research reports the experience of the use of digital games and learning objects, as a contribution in the teaching practice of licenciandos in mathematics and teachers of mathematics of public schools, using them to enhance the teaching-learning process, motivate students to learn And to give more meaning to your mathematical knowledge. As a result, we can mention the increase in students' motivation to participate in mathematics classes, the use of teachers and graduates in choosing and adopting tools to support learning and to improve the performance of said schools in the Education Development Index Basic.
\end{abstract}

RESUMO: A presente pesquisa relata a experiência do uso de jogos digitais e objetos de aprendizagem, como contribuição na prática docente de licenciandos em matemática e docentes de matemática de escolas pública, utilizando-os para potencializar o processo de ensino-aprendizagem, motivar os alunos a aprender e a dar mais significado ao seu conhecimento matemático. Como resultados pode-se citar o aumento da motivação dos alunos a participarem das aulas de matemática, a instrumentalização dos professores e dos licenciandos para a escolha e adoção de ferramentas apoio à aprendizagem e a melhoria de desempenho das referidas escolas no Índice de Desenvolvimento da Educação Básica.

\section{Introdução}

A matemática é uma linguagem que permite a reconstrução da realidade através de modelos. Por meio de seu ensino, procura trazer esses modelos para sala de aula de maneira didática, que permita possibilitar aos alunos a realização de um diálogo entre a matemática e as suas vidas. Sendo assim, é preciso que os professores tenham uma concepção que os leve a refletir, sempre que possível, sobre suas práticas pedagógicas. Essa reflexão ajuda na condução da construção de uma aprendizagem significativa para os alunos por ser esta, muitas vezes, uma aprendizagem que surge através das necessidades dos mesmos. Sendo que, muitas vezes, os professores na sua formação, em nível de graduação, não são formados no sentido de buscarem alternativas que os façam avançar em sua didática. Isto se deve ao fato de que os mesmos aprendem que a matemática deve ser ensinada apoiada em poucos recursos, particularmente, o uso do quadro e, mais fortemente, o uso do livro didático. 
É preciso ressaltar que há algum tempo estamos vivendo no mundo com diversas mudanças e os alunos vêm acompanhando essas mudanças interagindo com vários meios de comunicação. A escola, como um desses meios, não pode ficar distante da inovação que vem acontecendo e os professores, como um dos elementos importantes da escola, precisam ajudar com o amadurecimento desta. Para isso, precisam trabalhar não de maneira estanque, mas trazer algo externo aos muros da escola, para poder orientar os alunos sobre seu uso, como também ensinar algo novo. Torna-se importante, então, buscar novas estratégias didáticas, que o possibilitem refletir sobre sua prática e perceber que, em alguns momentos, essa prática não está ou não vem funcionando. Essa reflexão pode ser um elemento que o ajudará a reverter o quadro de baixos índices de desempenho dos alunos em matemática que vem sendo apresentado nas avaliações em larga escala, o que aponta que o ensino de matemática precisa, e muito, ser melhorado.

No contexto do ensino da matemática, a aprendizagem depende de ações que caracterizem experimentação, interpretação, visualização, indução, abstração, generalização e demonstração, as quais podem ser realizadas através da interação dos alunos com Tecnologias de Informação e Comunicação (TICs), como os jogos digitais e os objetos de aprendizagem, considerados poderosas ferramentas de apoio aos processos de ensino-aprendizagem.

\section{Tecnologias digitais: experiências com jogos digitais e outros objetos de aprendizagem}

A utilização de recursos tecnológicos aplicados na educação é assunto recorrente e Setzer (2001) traz a discussão sobre os benefícios de tais recursos, bem como possíveis estratégias de ensino para aplicação dos mesmos. Em seu livro intitulado "Meios eletrônicos e educação: uma visão alternativa" o autor apresenta as tecnologias que fazem parte do dia-a-dia dos ambientes educacionais e analisa os limites da influência delas no desenvolvimento ou no atrofiamento do pensamento, das ideias ou mesmo do seu físico e tenta "(...) conscientizar as pessoas do que são esses aparelhos e o que deveria significar a educação de um ponto de vista humano global" (SETZER, 2001, p. 13). Já Alonso (2001) apresenta uma proposta de estratégias diferenciadas para a utilização dessas tecnologias na educação.

ALVES (2008) usa o termo jogos digitais para se referir aos elementos tecnológicos que são utilizados nos PCs que apresentam narrativas, interatividade, interface, qualidade e realismo das imagens de forma diferenciada dos primeiros, isto é, mais simples, mais elementar. Esses elementos tecnológicos que também se valem da simulação tem hoje papel crescente nas atividades de pesquisa científica, de criação industrial, de gerenciamento, de aprendizagem, mas também nos jogos e diversões (sobretudo nos jogos interativos na tela).

A ação no jogo, tanto quanto no problema, envolve um objetivo único
que é vencer o jogo ou resolver o problema e, em ambos os casos, o
individuo se sente desafiado e motivado a cumprir tal objetivo. Atingir
o objetivo implica em dominar, em conhecer, em compreender todos
os aspectos envolvidos na ação e, portanto, produzir conhecimento
(Grando, 1995, p.77).

Partindo da premissa que o uso de jogos pode promover aprendizagens significativas aos seus usuários, inúmeros estudos têm sido realizados em todo o país a partir do desenvolvimento de experimentos com jogos, principalmente no ensino básico, 
como é o caso das "Olimpíadas de Jogos Digitais e Educação (OJE)", criada em Pernambuco, mas hoje realizada também no Rio de Janeiro, onde alunos das escolas públicas de ambos os estados organizam-se em equipes para competir em uma olimpíada de jogos educacionais, cujos resultados permitem verificar o quanto os jogos impactam as tarefas tipicamente escolares e, consequentemente, a aprendizagem dos alunos envolvidos e o despertar do interesse pelos estudos e pelo convívio escolar.

A partir da dimensão motivadora promovida pela OJE aos alunos das redes estaduais de ensino de Pernambuco e do Rio de Janeiro, se deparam com um ambiente invocador e desafiador que, segundo Meira (2010), perpassa 50\% do tempo de atividades escolares e que tem contribuído para a transformação dos cenários tradicionais da sala de aula.

No que se refere aos objetos de aprendizagem são definidos por Willey (2002) como qualquer recurso digital que pode ser reusado para apoiar a aprendizagem, considerando como objetos de aprendizagem desde imagens e gráficos, vídeos, sons, ferramentas até qualquer outro recurso educacional digital a ser utilizado para fins educacionais e que contenha sugestões sobre o contexto de sua utilização.

O estudo de Tarouco et al (2006) apresenta a estratégia de capacitação de professores e alunos para a construção de objetos de aprendizagem, exercendo o processo de autoria. Tais relatos de experiência descrevem casos de sucesso na utilização de jogos digitais e de objetos de aprendizagem e vislumbram suas potencialidades para usos educacionais, comprovando a importância destes recursos para a aprendizagem dos alunos e para formação do professor, sendo que existem também experiências específicas de investigação do uso desses recursos para o ensinoaprendizagem de conteúdos matemáticos, como o de Martins et al (2009), porém destinado somente para as séries iniciais do ensino fundamental.

Especificamente para o ensino da matemática o uso de jogos digitais e de objetos de aprendizagem podem trazer contribuições como: desenvolver a criatividade, a capacidade de reflexão, o senso crítico e as diferentes estratégias para a resolução de problemas. Também é apresentada, nos estudos de Moura (1994), Grando (1995, 2000, 2004) e Marco (2004), a capacidade de revelar e/ou desencadear conceitos matemáticos no processo de aprendizagem.

\section{Metodologia}

É nesse contexto que se insere o subprojeto intitulado "DIVERSÃO + APRENDIZAGEM = DIVERSAGEM: aprendendo a matemática por outros caminhos" que foi desenvolvido em 4 Escolas da Rede Pública Estadual do Rio Grande do Norte situadas nas cidades onde estão localizados dois dos polos de apoio presencial de uma universidade pública federal do Semi-Árido Potiguar. Por meio deste projeto, 40 professores-alunos da Licenciatura em Matemática foram inseridos como bolsistas em uma pesquisa de intervenção didática por meio da participação no Projeto Político Pedagógico das escolas, sob a orientação de 4 professores das referidas escolas, atuando como supervisores bolsistas, desenvolvendo atividades de extensão integradas ao ensino da didática de conteúdos matemáticos com a utilização de jogos digitais e objetos de aprendizagem.

O projeto fez parte do Programa Institucional de Bolsas de Iniciação à Docência (PIBID), uma das políticas públicas implementadas pela CAPES para incentivo à 
formação de professores através da mobilização de mobilizar instituições, docentes e estudantes que lidam com a formação de professores para a educação básica, com o intuito de socializar, debater e implementar práticas formativas referentes às licenciaturas. Para tanto, foi realizado um processo seletivo tanto para os alunos da Licenciatura em Matemática, quanto para os professores de matemáticas das escolas participantes do projeto que demonstraram interesse em participar da iniciativa. Posteriormente à seleção dos bolsistas foi dado início à implantação do projeto, cuja pesquisa em questão foi organizada em 4 fases:

- Fase I - Formação dos professores-alunos para o trabalho na didática de conteúdos matemáticos usando jogos digitais e seleção dos jogos a partir da correlação das potencialidades destes com as orientações dos Planos Curriculares Nacionais (PCNs) para cada um dos eixos da matemática;

- Fase II - Diagnóstico e análise a priori da situação de ensino-aprendizagem de matemática nas escolas antes da implementação do projeto e observação da prática docente no ensino de matemática nas escolas;

- Fase III - Intervenção nas escolas a partir do ensino de conceitos matemáticos para alunos do Ensino Fundamental II $\left(6^{\circ}\right.$ ao $9^{\circ}$ anos $)$ utilizando jogos digitais nos laboratórios de informática das escolas;

- Fase IV - Diagnóstico e análise a posteriori da situação de ensino-aprendizagem de matemática nas escolas com a implantação do projeto, análise do desenvolvimento da escola após a intervenção; análise dos impactos na prática docente após a intervenção; estudo comparativo da situação de ensino-aprendizagem de matemática entre as escolas do projeto.

A interação dos licenciandos com os alunos das escolas ocorreu de quatro diferentes formas: a) Como observadores na sala de aula de matemática; b) Planejando e realizando as aulas em laboratório; c) Na Olimpíada de Jogos Digitais; e, d) Em demais atividades extra-curriculares propostas pela escola. Tal interação caracteriza-se como ferramenta essencial, tanto para o aprendizado dos licenciandos sobre a prática docente, quanto para a motivação dos alunos das escolas.

Durante os momentos de interação com alunos e professores, ao levarmos novas práticas de ensino, transformamos também o modo de pensar dos professores de matemática das escolas. Por fim, pudemos perceber também que ao utilizarmos metodologias que incluem o uso de tecnologias como meio de interação, como é o caso dos objetos de aprendizagem e dos jogos digitais, os alunos ficam mais motivados a assimilarem os conteúdos.

\subsection{Ações de pesquisa}

$\mathrm{Na}$ Fase I ocorreu a formação dos professores-alunos para o ensino da Didática de conteúdos matemáticos por meio de jogos digitais e de objetos de aprendizagem, bem como a seleção dos jogos digitais e dos objetos de aprendizagem a partir da correlação das potencialidades destes com as orientações dos PCNs para cada um dos eixos da matemática, para só então ser realizado o planejamento das ações de intervenção nas escolas. Para a seleção dos objetos digitais de aprendizagem a serem utilizados, os licenciandos foram orientados à acessarem os principais bancos de objetos de aprendizagem e os selecionarem a partir de sua correlação com os conteúdos indicados nos PCNs. A partir da lista inicial de objetos, foram selecionados os que 
melhor permitiam o trabalho com os conteúdos, segundo critérios conceituais como completude, complexidade, nível de aprofundamento e correlação com a prática. $\mathrm{O}$ critério técnico adotado para seleção das ferramentas foi que pudessem ser executadas localmente, em função das condições precárias de internet nas escolas. Os professores de matemática auxiliaram os alunos na identificação dos conteúdos a serem trabalhados com cada um dos objetos de aprendizagem selecionados, bem como discutindo o método, a melhor forma de aplicar a ferramenta no ensino dos conteúdos. Essas discussões eram realizadas mensalmente, nas reuniões de planejamento das aulas práticas em laboratório, das quais resultavam os planos de aula para cada aula semanal de cada uma das turmas do $6^{\circ}$ ao $9^{\circ}$ anos.

Algumas das ferramentas obtidas em bancos de objetos de aprendizagem públicos e selecionadas para o trabalho com os alunos foram: Jogo do Enigma - para trabalhar com operações com números racionais, mais especificamente com frações; Cubo vermelho, vitral quebrado e ponte escura - para trabalhar raciocínio lógico; Jogo OX - para trabalhar potenciação; Calculadora quebrada e apocalipse - para trabalhar com números e operações; Tangram - para trabalhar geometria plana; Torre de Hanói - para trabalhar com números naturais.

Já na Fase II, foi realizado o diagnóstico da situação de ensino-aprendizagem de matemática em cada escola, baseado no IDEB, a análise a priori da situação de ensino-aprendizagem de matemática em cada escola e a observação da prática docente no ensino de matemática nas escolas, através da aplicação de questionários e realização de entrevistas com alunos, professores e equipe gestora e da realização de testagens com os alunos; instrumentos estes que possibilitaram aos licenciandos a participação na elaboração, aplicação e análise dos dados coletados; experiência de pesquisa com a qual não haviam tido contato até então.

Na Fase III foi realizada a formação dos professores das escolas para o ensino de conceitos matemáticos por meio de jogos digitais e objetos de aprendizagem através de oficinas de exploração, bem como a efetivação do ensino de conceitos matemáticos para alunos do $6^{\circ}$ ao $9^{\circ}$ anos, utilizando objetos de aprendizagem e jogos digitais. Tal formação se deu a partir da construção colaborativa, pelos professores de matemática e licenciandos, de estratégias de abordagem dos conteúdos com o apoio didático das ferramentas selecionadas, com a mediação da coordenação do projeto e, algumas vezes, da coordenação pedagógica da escola. A característica colaborativa desse trabalho possibilitou uma maior aceitação do uso das ferramentas pelos docentes, uma apropriação mais rápida da ferramenta pelos docentes e a mobilização dos saberes para aplicação na prática com as ferramentas.

$\mathrm{Na}$ Fase IV foi realizado um novo diagnóstico da situação de ensinoaprendizagem e matemática em cada escola, o levantamento de dados sobre o desempenho da escola no IDEB, a observação da prática docente no ensino de matemática a posteori, as análises do desenvolvimento da escola após a intervenção, dos impactos na prática docente e da situação de ensino-aprendizagem de matemática em cada escola após a intervenção. Também foi realizado um estudo comparativo da situação de ensino-aprendizagem de matemática nas escolas, comparando-se os diagnósticos, observações e análise a priori com os realizados a posteori. Para que as fases de implantação pudessem ser realizadas, a pesquisa contou com 4 etapas 
metodológicas, assim organizadas: a) coleta de dados; b) registro de dados; c) análise de dados e, d) avaliação.

$\mathrm{Na}$ coleta de dados foi observada a legislação vigente, assim como os documentos norteadores (PCNs) e os projetos pedagógicos das escolas. Também foi realizada uma pesquisa etnográfica e o uso de instrumentos e técnicas de coleta de dados, como: aplicação de questionários, entrevista e grupos focais. Para o registro de dados foram utilizadas duas estratégias diferentes: a) os dados qualitativos serão organizados de acordo com os princípios da análise de conteúdo, utilizando os softwares NVIVO e AtlasTI; e, b) os dados quantitativos serão tabulados de acordo com os princípios da análise estatística, utilizando o software SPSS. Já a análise de dados foi realizada utilizando quatro diferentes estratégias: a) análise estatística; b) análise de conteúdo; c) análise documental; e, d) análise de ferramentas.

\subsection{Ações de formação}

As ações de formação foram organizadas em dois tipos: a) ações de capacitação; e, b) ações de planejamento. As ações de capacitação envolveram a preparação dos alunos para o planejamento das aulas, orientações sobre a avaliação, seleção e utilização de objetos de aprendizagem e jogos digitais de aprendizagem, avaliação de livros didáticos, elaboração de instrumentos de avaliação e análise dos protocolos de aplicação dos instrumentos.

As ações de planejamento envolveram os conteúdos e a escolha das ferramentas, as ações em sala de aula, a elaboração dos planos de aula, as aulas no laboratório de informática, encontros mensais para planejamento geral das ações junto à coordenação do subprojeto, além das Olimpíadas de Jogos Digitais e Matemática em cada escola (realizado no segundo semestre de cada ano de projeto), para a qual os alunos se organizavam em equipes, participavam de uma eliminatória na sua escola e as equipes vencedoras representavam suas escolas na final, realizada na universidade, bem como premiação e entrega de medalhas aos vencedores.

\subsection{Avaliação}

A avaliação das atividades realizadas pelos atores do subprojeto foi co-participativa, formativa e processual, envolvendo os gestores e professores das escolas, o coordenador de área e os supervisores do subprojeto, visando não a avaliação do sujeito, mas a avaliação dos impactos da implantação do projeto nas escolas. Também foi incluída, no processo avaliativo, a auto-avaliação de bolsistas de iniciação à docência, supervisores e coordenador de área. Para cada etapa de avaliação foram elaborados instrumentos adequados às atividades realizadas, como: questionários com questões fechadas e abertas, entrevistas semi-estruturadas e roteiros para realização de grupo focal.

O registro das atividades e percepções dos atores envolvidos foi realizado através de relatórios parciais e finais, redigidos com base nas observações e nas gravações de áudio realizadas durante a atuação nas escolas. Outro fator importante foi a possibilidade da avaliação processual, realizada nos momentos de aulas em laboratório, onde os professores de matemática puderam perceber o nível de apropriação dos alunos sobre o conteúdo trabalhado em sala de aula. 


\section{Discussão dos resultados}

Os resultados alcançados foram categorizados segundo os atores por eles beneficiados, como segue: a) alunos da UFERSA; b) professores das escolas parceiras; c) alunos das escolas parceiras; d) escolas parceiras; e) Curso de Licenciatura em Matemática a Distância da UFERSA.

\subsection{Para os alunos UFERSA}

Como resultados principais alcançados em benefício dos alunos da UFERSA participantes como bolsistas da pesquisa pode-se citar a preparação destes para a carreira docente na área de matemática em escolas públicas, a partir do conhecimento do contexto educacional das escolas, da observação da prática docente, da experiência de intervenção supervisionada e, principalmente, através do planejamento das aulas e dos registros das atividades realizadas, que fizeram com que eles fossem capazes de refletir sobre a própria prática.

As formações/orientações para implantação do projeto e intervenção em sala de aula permitiram a preparação dos alunos bolsistas para a atuação em projetos de extensão o que, segundo os licenciandos, quando questionados sobre a participação no projeto. Outro aspecto importante foi a preparação dos alunos bolsistas para a realização de pesquisas científicas sobre a prática docente em educação matemática, a partir de capacitações que os qualificaram a elaborar, aplicar e analisar os instrumentos de coleta de dados, bem como da capacitação para avaliação de livros didáticos a partir das dimensões apresentadas nos PCN's.

\subsection{Para os professores das escolas parceiras}

No que se refere aos professores das escolas parceiras, atuantes no projeto como bolsistas de supervisão, receberam a formação continuada sobre a avaliação de jogos digitais e objetos de aprendizagem relacionando-os aos conteúdos do currículo escolar, o que os preparou para a atuação como supervisores dos licenciandos em matemática.

Tanto as formações recebidas, quanto as orientações e acompanhamentos da coordenação do projeto contribuíram para a melhoria na qualidade do trabalho como docente e a melhoria da qualidade do ensino na área de matemática, visto que foram identificadas mudanças de postura dos professores em relação às metodologias adotadas; sendo registradas diversas ocorrências de uso dos objetos de aprendizagem pelos professores para demonstração de aplicação prática dos conteúdos matemáticos em sala de aula.

Um resultado importante, que cabe ser ressaltado, é a valorização do professor da rede pública de educação básica enquanto profissional da educação, tanto por parte dos próprios alunos, como dos colegas professores (que valorizaram a seleção do colega para participação no projeto) e das direções das escolas, que não somente autorizaram a realização do projeto, como também apoiaram toda a sua execução.

\subsection{Para os alunos das escolas parceiras}

Os alunos das escolas parceiras obtiveram como benefícios a melhoria da qualidade da aprendizagem na área de matemática, em função do uso dos jogos digitais e dos objetos de aprendizagem para auxiliar o ensino dos conteúdos.

$\mathrm{O}$ uso de jogos digitais e de objetos de aprendizagem para o ensino da matemática nas turmas do $6^{\circ}$ ao $9^{\circ}$ anos do ensino fundamental comprovadamente 
contribuíram para a prática docente, visto que potencializaram o processo de ensinoaprendizagem, motivaram os alunos a aprender e possibilitaram que os alunos dessem mais significado ao seu conhecimento matemático. Também foram registrados dois resultados importantíssimos: o aumento do interesse dos alunos pela disciplina de matemática o estímulo aos alunos das escolas públicas para o ingresso na universidade pública.

\subsection{Para as escolas parceiras}

As escolas parceiras, nas quais a pesquisa foi realizada, obtiveram como principal resultado, a contribuição para a melhoria na qualidade do ensino na escola, visto que seus professores foram capacitados e estimulados a utilizarem um espaço antes subutilizado, o laboratório de informática. Também se pode citar a melhoria da qualidade do ensino e aprendizagem na área de matemática e o aumento da frequência das atividades experimentais na escola.

\subsection{Para o Curso de Licenciatura em Matemática à Distância da UFERSA}

Já no que se refere ao curso de Licenciatura em Matemática à Distância da UFERSA, pode-se dizer que a articulação do curso com as escolas e a comunidade foi um dos principais benefícios do projeto, visto que contribuiu para a consolidação da proposta de formação prevista no Projeto Pedagógico do Curso. Outro resultado importante foi a melhoria da qualidade do estágio supervisionado da licenciatura nas escolas da rede pública. Além destes, um dos principais problemas dos cursos à distância foi aqui minimizado, através da implantação do presente projeto: a evasão dos alunos do curso, que foi diminuída com o envolvimento dos alunos em atividades de extensão.

\subsection{Resultados não previstos}

Como resultados não previstos no planejamento das ações e no estabelecimento das metas a serem alcançadas pelo projeto cabe ressaltar a melhoria dos índices educacionais das duas escolas situadas na cidade de Mossoró, que alcançaram índices mais altos dos que os anteriores no IDEB.

No caso do Centro de Educação Integrada Professor Eliseu Viana, o IDEB de 2011 foi de 2,6, enquanto que o de 2013, posterior à realização do projeto, foi de 3,3, correspondendo a um aumento superior a $25 \%$. Quando comparados estes resultados às metas previstas para os mesmos períodos, verifica-se que a escola alcançou a sua meta em aproximadamente $79 \%$ em 2011, passando para, aproximadamente, $89 \%$ de cumprimento da meta em 2013. Poder-se-ia dizer que este é um resultado isolado, porém também se repetiu na Escola Estadual Ambulatório Padre Dehon, cujo IDEB em 2011 foi de 3,1, enquanto o de 2013, posterior à implantação do projeto, foi de 3,9, correspondendo a um aumento também superior a $25 \%$. Quando comparados os resultados às metas previstas para os mesmos períodos, verifica-se que a escola superou a sua meta em 3\% em 2011, passando para uma superação de aproximadamente $14 \%$ da meta prevista para 2013.

\section{Considerações finais}

Apesar de ter sido um projeto inovador, o primeiro subprojeto do PIBID com bolsas específicas para os alunos de um curso à distância, este foi extremamente exitoso, contrariando as expectativas da comunidade acadêmica que pensava não ser possível a realização de um projeto de extensão exigindo tamanho envolvimento de alunos de um 
curso à distância. $\mathrm{O}$ que pode ser confirmado através dos relatos dos próprios alunos que relataram que a sua participação no projeto do PIBID foi o fator motivador para eles não desistam do curso, apesar das dificuldades enfrentadas ao longo do curso; fato este que corrobora a importante mudança de postura dos licenciandos em relação ao seu compromisso com o curso de licenciatura.

Objetivos instrucionais estabelecidos no início do projeto como o desenvolvimento de ações acadêmicas da Licenciatura em Matemática a Distância da UFERSA por meio da integração do ensino, pesquisa e extensão articulando ações da formação docente com a educação básica do sistema público, relacionando-as com as disciplinas de práticas e ensino e o estabelecimento de parcerias com escolas da rede pública buscando melhorar a qualidade do ensino de Matemática na educação básica a partir da integração de jogos digitais o objetos de aprendizagem nas práticas adotadas pelos docentes foram amplamente alcançados.

Já os objetivos da valorização do magistério e da valorização do espaço da escola pública como campo de experiência para a construção do conhecimento na formação de professores de matemática para a educação básica no uso de novas tecnologias, extrapolaram as expectativas dos pesquisadores, visto que o incentivando aos professores da área de Matemática a participarem de práticas inovadoras no processo de ensino-aprendizagem acabou não só por motivar os alunos bolsistas, quanto incentivar os outros colegas professores e contagiar o ambiente escolar.

Outros dois objetivos que superaram as expectativas dos pesquisadores foram o da elaboração de experiências práticas que contribuam para a melhoria da qualidade do ensino de matemática nas escolas parceiras e o de proporcionar aos professores de Matemática a participação nas ações, pois tais experiências metodológicas e práticas docentes inovadoras, articuladas com a realidade da escola e da região do semiárido e da sociedade tecnologizada, acabaram não só por motivar os alunos das escolas públicas à participar das aulas de matemática com mais entusiasmo, como também abriram nos perspectivas motivacionais de acesso à universidade.

Tão importante quanto os objetivos institucionais, da valorização do magistério e da valorização do espaço da escola pública, da elaboração de experiências práticas e de proporcionar aos professores de Matemática a participação nas ações são as expectativas dos alunos, diagnosticadas no início do projeto e validadas ao final foram integralmente alcançadas e dizem respeito à mudanças nas aulas de Matemática através de: a) Inserção de novas tecnologias nas atividades; b) Inserção de novos métodos de avaliação; c) Modificação nas formas de ensino através da adoção de jogos e outros elementos de aprendizagem; d) Elevação das notas das atividades desenvolvidas por eles; e, e) Que passassem a gostar de Matemática.

Cabe ressaltar que, apesar da criação e modificação de artefatos ser considerada um novo e promissor campo de pesquisa, este não foi um objeto da presente pesquisa, pois o considerado primordial foi a apropriação dos professores sobre as ferramentas/recursos e a capacidade destes de analisar e avaliar de que maneira eles influenciam na prática da didática da matemática em sala de aula e/ou no laboratório de informática. Desta forma foi possível observar a influência destes recursos não só no trabalho individual do professor de matemática, como também no seu trabalho coletivo com de planejamento e execução das aulas juntamente com os licenciandos em matemática e da sua interação com os alunos durante as aulas em laboratório. 
Tal perspectiva nos permite uma base fundamental do funcionamento desse tipo de projeto nas escolas públicas do Rio Grande do Norte, preparando os professores e licenciandos para selecionarem de forma eficaz os recursos de apoio a aprendizagem e preparando-os para futuros projetos, como por exemplo, o desenvolvimento de seus próprios objetos de aprendizagem ou outras ferramentas educacionais.

\section{Referências}

ALONSO, A. S. M.(2001). O método e as decisões sobre os meios didáticos. In: SANCHO, J. M.(org). Para uma tecnologia educacional. Porto Alegre: ArtMed, p.72-96.

ALVES, L. (2008). Relações entre os jogos digitais e aprendizagem: delineando percurso. In: Educação, Formação \& Tecnologias, vol. 1 (2), Novembro.

GRANDO, R. C. (2004). O jogo e a Matemática no contexto da sala de aula. São Paulo: Paulus, 115 p.

GRANDO, R. C. (2000). O conhecimento matemático e o uso de jogos na sala de aula. 224 p. Tese (Doutorado em Educação). Campinas: FE/UEC.

GRANDO, R. C. (1995). O Jogo e suas Possibilidades Metodológicas no Processo EnsinoAprendizagem da Matemática. Dissertação (Mestrado em Educação, subárea: Matemática). Campinas: UNICAMP.

MARCO, F. F. de. (2003). Estudo dos processos de resolução de problema mediante a construção de jogos computacionais de matemática no ensino fundamental. 140 p. Dissertação (Mestrado em Educação). Campinas: FE/UEC.

MARTINS, E. L.; SERRES, F. F.; BASSO, M. V. A.; WEIAND, V. L. (2009). Interação de recursos digitais e não-digitais no ensino de matemática nas séries iniciais. In: Encontro Gaúcho de Educação Matemática. Relato de Experiências. Ijuí: Unijui, junho.

MEIRA, L. (2010). Novos Caminhos para a Educação: cultura digital, jogos e divertimento eletrônico. In: Plug - Programa de Disseminação de Software Livre nas Escolas Públicas do Recôncavo da Bahia. Abril.

MOURA, M. O. (1994). A Séria Busca no Jogo: do lúdico na Matemática. In: A Educação Matemática em Revista. Revista da SBEM, ano 2, n.3.

SETZER, V. W. (2001). Meios eletrônicos e educação: uma visão alternativa. São Paulo: Escrituras Editora.

TAROUCO, L. M. R.; KONRATH, M. L. P.; CARVALHO, M. J. S. (2006). Formação de professores para produção e uso de objetos de aprendizagem. In: Novas tecnologias na educação. V. $4 \mathrm{~N}^{\mathrm{o}}$ 1, Julho. Porto Alegre: CINTED-UFRGS.

WILLEY, D. A. (2002) Connecting learning objects to instructional design theory: A definition, a metaphor, and a taxionomy. Disponível em: $<$ http://reusability.org/read/>. Acesso em (25/02/2011). 